Check for updates

Cite this: RSC Adv., 2017, 7, 50527

\title{
Study of structural, optical and magnetic properties of cobalt doped ZnO nanorods
}

\author{
Anupama Chanda, (D) *a Shipra Gupta, ${ }^{\text {b }}$ M. Vasundhara, (D) *c Shalik R. Joshi, ${ }^{\text {, }}$ \\ Geeta R. Mutta ${ }^{e}$ and Jai Singh*a
}

Cobalt doped zinc oxide nanoparticles (NPs) and nanorods (NRs) were synthesized by a simple chemical method. An increase in the formation of nanorods with an increase in cobalt doping is found to occur from scanning electron microscopy and transmission electron microscopy studies. Powder X-ray diffraction, high-resolution transmission electron microscopy, and selected area electron diffraction confirm the formation of a wurtzite crystal structure of $\mathrm{ZnO}$. Shifting and broadening of the bands at $437 \mathrm{~cm}^{-1}$ and $579 \mathrm{~cm}^{-1}$ in the micro-Raman study of Co-doped $\mathrm{ZnO}$ nanostructures indicates the incorporation of $\mathrm{Co}$ in $\mathrm{ZnO}$. Shifting of the absorption edge to lower wavelength and blue shift of the band gap is observed in UV-visible spectra of Co-doped $\mathrm{ZnO}$ samples. Field-dependent magnetization measurements exhibit diamagnetic behavior down to $2 \mathrm{~K}$ in the case of $\mathrm{ZnO}$ whereas Co-doped $\mathrm{ZnO}$ samples show coexistence of superparamagnetic and ferromagnetic behavior at room temperature and at $2 \mathrm{~K}$. The observed ferromagnetism may have originated due to the exchange interaction between the localized d electrons in $\mathrm{Co}^{2+}$ atoms and free carriers generated due to Co-doping as well as due to cobalt clustering in the Co-doped samples.

Received 31st July 2017

Accepted 17th October 2017

DOI: $10.1039 / \mathrm{c} 7 \mathrm{ra0} 8458 \mathrm{~g}$

rsc.li/rsc-advances key parameters. One of the major challenges for semiconductor spintronics devices is to develop suitable magnetic semiconducting materials that will effectively allow spin-polarized carriers to be injected, transported, and manipulated.

A lot of research has been done on diluted magnetic semiconductors based on II-VI semiconductors such as CdMnTe and $\mathrm{ZnMnSe}^{7-9}$ in which the valence of the cation matches with common magnetic ions such as Mn. Although it is easy to prepare such materials, it is difficult to make p- or n-type II-VI based DMS, which make these materials less attractive for applications. After discovery of the hole induced ferromagnetic order in p-type InMnAs ${ }^{10}$ and GaMnAs, ${ }^{11}$ a lot of studies have been carried out on III-V based DMS system ${ }^{12-17}$ but unfortunately room temperature ferromagnetism could not be observed in GaMnAs. Since then a large number of efforts has been carried out to find the possibility of room temperature ferromagnetism in III-V based DMS such as GaN, GaSb, InAs ${ }^{18-21}$ and oxide-based DMS such as $\mathrm{ZnO}, \mathrm{TiO}_{2}, \mathrm{SnO}_{2}, \mathrm{In}_{2} \mathrm{O}_{3}$ etc. ${ }^{22-29}$

Zinc oxide (ZnO), a direct and wide band gap (3.37 eV) II-VI oxide semiconductor has high exciton binding energy (nearly 60 $\mathrm{meV}$ at room temperature), good transparency and long term stability. ${ }^{30,31}$ It has been given due importance because of its excellent optoelectronic, sensing and piezoelectric properties. ${ }^{32}$ It finds various technological applications like sensors, light emitting diodes, lasers, solar cells, resistive switching devices, photocatalysts and most recently in spintronics, etc. ${ }^{33-42}$ It has strong room temperature luminescence properties like ZnS nanoparticles $^{\mathbf{4 3}}$ but the luminescence efficiency can be

\footnotetext{
a Department of Physics, Dr Harisingh Gour Central University, Sagar, M.P-470003, India.E-mail: anupamamatsc@gmail.com; jai.bhu@gmail.com

${ }^{b}$ Indian Institute of Technology (BHU), Varanasi, Uttar Pradesh-221005, India ${ }^{c}$ CSIR-National Institute for Interdisciplinary Science and Technology, Trivandrum695 019, Kerala, India.E-mail: mvas@niist.res.in

${ }^{d}$ Institute of Physics, Bhubaneswar, Odisha-751005, India

${ }^{e}$ Nano-Materials Laboratory, School of Engineering and Physical Sciences, Heriot Watt University, Edinburgh EH14 4AS, UK
} 
enhanced by using $\mathrm{ZnO} / \mathrm{ZnS}$ nanocomposites ${ }^{44}$ or core shell of ZnS:Mn/ZnO nanocrystals. ${ }^{45} \mathrm{ZnO}$ is biocompatible and has been used as good antibacterial agent as well. ${ }^{46}$ After the theoretical prediction of Dietl et al. ${ }^{47}$ about the room temperature ferromagnetism of GaN and $\mathrm{ZnO}$ thin films, Lin et al. ${ }^{48}$ experimentally demonstrated room temperature ferromagnetism in Co-doped ZnO thin films. Optical properties such as absorption and photoluminescence can enhance the understanding of the mechanisms of high temperature ferromagnetism in transition metal doped ZnO. As a dopant, Co is able to modulate both the optical and magnetic behavior of $\mathrm{ZnO}$ due to its abundant electron states. ${ }^{49}$ Its ionic radius as well as its divalent state ensures a high solubility in $\mathrm{ZnO}^{50}$ due to which it has been widely used for tuning the optical as well as the magnetic behavior of ZnO. According to the $a b$ initio calculations by Sato and Yoshida ${ }^{51}$ antiferromagnetism is stable in Mn-doped $\mathrm{ZnO}$ while ferromagnetism is stable in other transition metal doped $\mathrm{ZnO}$ (V, Cr, Fe, Co, Ni). Although several experimental investigations have shown room temperature ferromagnetism in Codoped $\mathrm{ZnO}^{52-55}$ still there is a lack of clear explanations regarding the origin of ferromagnetism. Various techniques like sol-gel, hydrothermal, chemical synthesis, chemical vapor deposition, thermal evaporation, etc. ${ }^{56-60}$ have been used for the production of Co-doped $\mathrm{ZnO}$ nanoparticles as well as thin films. It has been observed that magnetic behavior of the materials varies due to variation in growth synthesis and dimensionality. ${ }^{61}$ Both intrinsic parameters like oxygen vacancy, $\mathrm{Zn}$ interstitial and extrinsic parameters like magnetic clusters or separate phase formation have been observed to be responsible for different kind of magnetic behaviour. ${ }^{62-65}$ Several studies have reported on the grain boundary defect mediated ferromagnetism in Co-doped films. ${ }^{6-69}$ Recently, Aravindh et al. predicted room temperature ferromagnetism arising due to exchange coupling of a pair of Co atoms at the grain boundary, a new observation based on first-principle calculations. ${ }^{69}$ Numerous studies have been done on the behavior of Co-doped ZnO thin films and nanoparticles, but one dimensional DMS materials are not widely reported. ${ }^{70-73} \mathrm{Li}$ et $a .^{74}$ observed that enhancement in ferromagnetism in Co-doped $\mathrm{ZnO}$ films was correlated to the degree of orientation of the films while a high degree of $c$-axis orientation is desirable in Co-doped $\mathrm{ZnO}$ nanorods to optimize the magnetic behavior. Liu et al. ${ }^{75}$ studied photoluminescence behavior of vertically aligned $\mathrm{Zn}_{1-x} \mathrm{Co}_{x} \mathrm{O}$ nanorods grown by hydrothermal route while Cui et al. ${ }^{76}$ reported the magnetic behavior of $\mathrm{Zn}_{1-x} \mathrm{Co}_{x} \mathrm{O}$ nanorods. Although there are several reports on the synthesis of nanoparticles (NPs) by wet chemical route, there are very few reports on the formation of nanorods (NRs) without using any substrate/seed layer by this method. ${ }^{55,60,65,77}$ The present study investigates the structural, optical and magnetic behavior of pure and Codoped ZnO NPs as well as NRs synthesized by a simple, lowcost chemical method.

\section{Experimental details}

Synthesis of un-doped and Co-doped (5 at\%, 10 at\%) $\mathrm{ZnO}$ nanostructures were carried out using zinc chloride $\left(\mathrm{ZnCl}_{2}\right)$, sodium hydroxide $(\mathrm{NaOH})$ and cobalt chloride $\left(\mathrm{CoCl}_{2}\right)$ as the starting materials. Zinc chloride was first dissolved in $50 \mathrm{ml}$ of distilled water, and after complete dissolution of $\mathrm{ZnCl}_{2}$, some amount of $\mathrm{NaOH}$ solution (dissolved in $50 \mathrm{ml}$ distilled water) was added under constant stirring drop by drop (during this period calculated amount of cobalt chloride $\left(\mathrm{CoCl}_{2} \cdot 6 \mathrm{H}_{2} \mathrm{O}\right)$ was added for cobalt doping). The reaction was allowed to proceed for two hours at room temperature. After complete addition of $\mathrm{NaOH}$ into the solution of $\mathrm{ZnCl}_{2}$, the solid and the solution phases were separated by the centrifugation process and then the solid was washed with distilled water several times to make that free of salt and at the end with ethanol to absorb all the water molecules present in that solid solution. A white color solid was obtained which was dried at $800{ }^{\circ} \mathrm{C}$ for 24 hours and then grinded for the uniformities of the powder (NPs/NRs). The crystal structure and phase purity of the powdered samples were analyzed by X-ray powder diffraction (XRD) technique (PANalytical-Empyrean Diffractometer) using $\mathrm{Cu} \mathrm{K} \alpha$ radiation of wavelength $1.5404 \AA$ and scanning size of $0.01^{\circ}$ from $15^{\circ} \leq \theta$ $\leq 100^{\circ}$. Rietveld refinement of the diffraction patterns was carried out using the Fullprof software. The morphologies of the NPs and NRs were investigated by scanning electron microscope (SEM, (JEOL-SEM 5601v, Tokyo, Japan)) and transmission electron microscope, (TEM, (FEI Tecnai F20, operated at $300 \mathrm{kV})$ ) and the crystal planes were found out from selected area electron diffraction (SAED) pattern. Micro-Raman scattering study was carried out with $514 \mathrm{~nm}$ laser in backscattering geometry on a T64000 triple monochromator Horiba Jobin Yvon system having a liquid nitrogen cooled CCD detector. A Shimadzu (model UV2401) UV-visible-spectrophotometer coupled with an integrating sphere was used for performing UV-visible absorbance measurements. An excitation wavelength of $325 \mathrm{~nm}$ from a xenon lamp of Varian fluorescence spectrometer (Fluorolog Jobin Yvon, Horiba, JAPAN) was employed to study the steady-state photoluminescence (PL) properties. Magnetic measurements of the samples were made as a function of temperature and applied field using a vibrating sample magnetometer attached to a physical property measurement system supplied by Quantum Design Inc., USA.

\section{Results and discussion}

The morphology of the samples was studied by scanning electron microscope. Fig. 1(a-c) shows SEM image and the corresponding EDS pattern (d, e and f) taken on $\mathrm{ZnO}, 5 \%$ and $10 \%$ Co-doped ZnO samples respectively. Nanoparticles can be clearly seen in ZnO samples while 5\% Co-doped sample shows few nanorods along with nanoparticles and large number of nanorods can be seen in 10\% Co-doped sample. SEM analysis shows increase in nanorods formation with increase in cobalt doping concentration which is discussed more in TEM section analysis. Elemental analysis was done by EDS which shows presence of zinc and oxygen in $\mathrm{ZnO}$ powder while Co-doped ZnO samples show presence of cobalt along with zinc and oxygen. Energy-dispersive X-ray spectroscopy analysis confirms the presence of $\mathrm{Co}$ in $\mathrm{ZnO}$ matrix. 


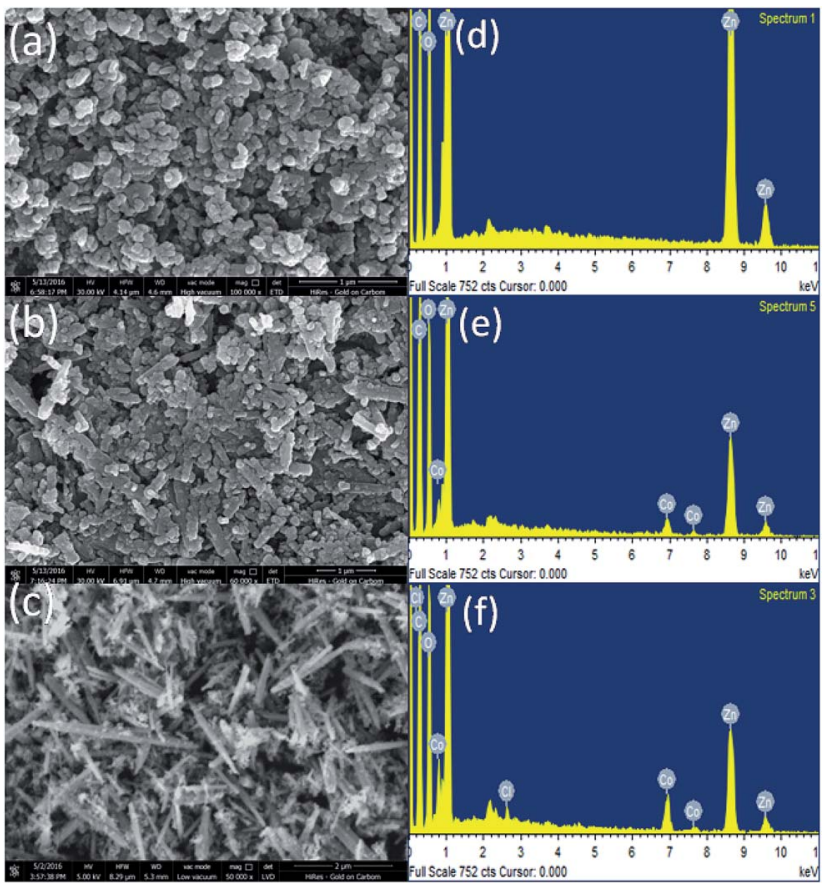

Fig. 1 SEM images of (a) $\mathrm{ZnO}$ (b) $\mathrm{ZnO}-5 \% \mathrm{Co}$ (c) $\mathrm{ZnO}-10 \% \mathrm{Co}$ (d) EDS taken on $\mathrm{ZnO}$, (e) $\mathrm{ZnO}-5 \% \mathrm{Co}$ (f) $\mathrm{ZnO}-10 \% \mathrm{Co}$ with proper indexing.

To further elucidate the size and structures of nanoparticles and nanorods TEM was carried out. Fig. 2 shows the TEM image of all the samples. Fig. 2(a) indicates the TEM image of undoped $\mathrm{ZnO}$ nanoparticles of sizes varying from 22 to $28 \mathrm{~nm}$. The varying size is due to agglomeration of particles. NRs of

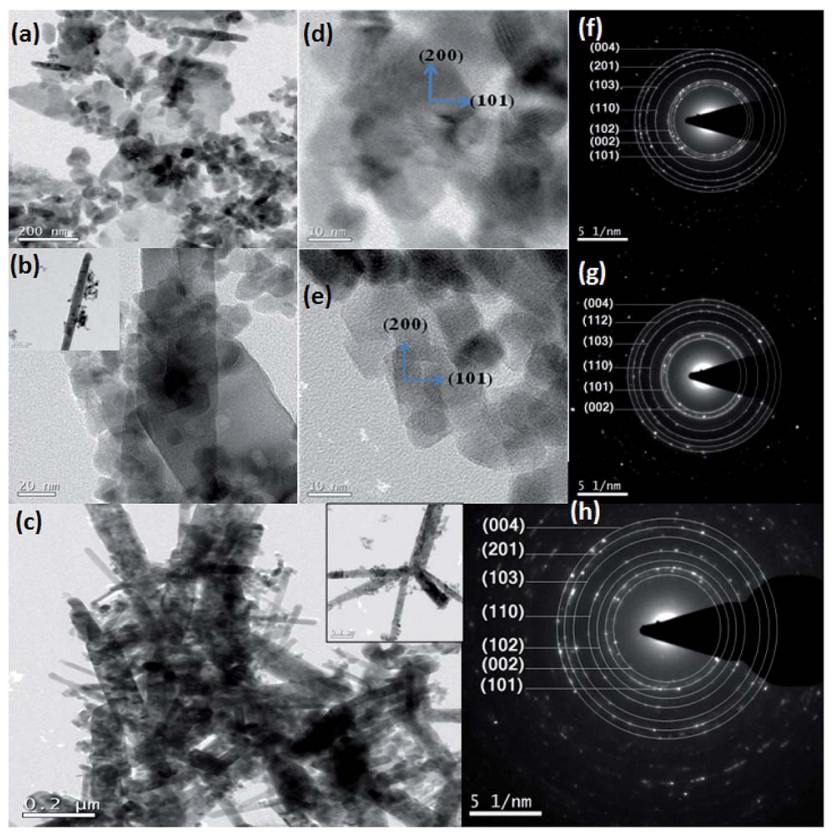

Fig. 2 TEM images of (a) $\mathrm{ZnO}$ (b) $\mathrm{ZnO}-5 \% \mathrm{Co}$ (inset shows a single nanorod) (c) $\mathrm{ZnO}-10 \% \mathrm{Co}$ (inset shows distinct nanorods), HRTEM image of (d) $\mathrm{ZnO}-5 \% \mathrm{Co}$ (e) $\mathrm{ZnO}-10 \% \mathrm{Co}$, SAED patterns of (f) $\mathrm{ZnO}$ (g) $\mathrm{ZnO}-5 \% \mathrm{Co}$ (h) $\mathrm{ZnO}-10 \% \mathrm{Co}$ indexed properly. sizes 60-80 $\mathrm{nm}$ diameter and length $400-500 \mathrm{~nm}$ can be seen in $5 \%$ and $10 \%$ Co-doped $\mathrm{ZnO}$ samples (Fig. 2(b and c)). It can be seen that with increasing Co concentration the density of NRs has been increased which are thought to be due to participation of more Co atoms in producing NRs. It can be inferred that $\mathrm{ZnO}$ sample shows nearly spherical shaped NPs while 5\% Co doped sample shows NRs along with irregular shaped particles and high concentration (10\%) Co-doped sample produces large number of NRs. The difference of the crystal growth velocities in different directions causes changes in surface morphology. In $\mathrm{ZnO}, c$-axis exhibits the highest growth rate due to the structure and surface anisotropy. ${ }^{77}$ The addition of Co ion in precursor solution induces thermodynamic barrier, ${ }^{\mathbf{6 5}, 78}$ which slows down the nucleation as well as the growth rate of primary nuclei. The effective ions have more time to deposit uniformly on the nuclei along the $c$-axis. So, the growth along $c$-axis direction has a faster rate than that along other directions due to which aspect ratio of $\mathrm{Co}$ doped $\mathrm{ZnO}$ nanorods increases as well as there is increase in the density of NRs with more dopant incorporation. From HRTEM image of 5\% and 10\% Co-doped samples the $d$-spacing of the crystal plane is found out to be of 0.271 and $0.269 \mathrm{~nm}$ respectively which corresponds (200) plane of hexagonal wurtzite structure. From this it can be inferred that the nanorod growth takes place along the $c$-axis i.e. along (200) as shown by the arrow in Fig. 2(d and e) for $5 \%$ and $10 \%$ doped samples. It has been observed that Co doping plays an important role in producing nanorods of different sizes which is in corroboration with the earlier reports. ${ }^{77}$

The SAED pattern taken on un-doped and Co-doped samples show clear distinct rings corresponding to different planes of hexagonal wurtzite ZnO structures (shown in Fig. 2(f-h)). The planes corresponding to different rings have been found out by calculating the $d$-spacing using Image-J software which is in agreement with the planes obtained in XRD.

The structural parameters and phase purity have been studied using powder X-ray diffraction and Full-proof software. The XRD patterns of Co-doped ZnO samples with varying dopant concentrations from $0 \%$ to $10 \%$ are shown in Fig. 3(a). All the samples are found to crystallize in single phase hexagonal crystal structure $\left(P 6_{3} m c\right.$ space group). All the peaks are sharp, properly indexed and well in agreement with that of standard datasheet (JCPDS-036-1451) corresponding to the hexagonal wurtzite. ${ }^{79}$ The most intense peak (101) (shown in the inset of Fig. 3(a)) shows a clear shift towards lower $2 \theta$ value as well as a decrease in intensity in Co-doped $\mathrm{ZnO}$ samples indicating the incorporation of $\mathrm{Co}$ in $\mathrm{ZnO} .^{80}$ No other diffraction peak has been detected related to Co metal or oxides in any of the samples doped up to $5 \%$. However, an additional diffraction peak related to secondary phases of Co metal has been found in the XRD pattern of $10 \%$ Co-doped $\mathrm{ZnO}$ samples.

There are several reports which indicate that Co has a limited solubility in ZnO. ${ }^{\mathbf{1 1}}$ Yeng et al. synthesized Co-doped ZnO materials followed by the hydrothermal process using zinc and cobalt nitride and observed the appearance of the second phase at $9.9 \%$ Co in $\mathrm{ZnO}^{82}$ In our case, we have seen very small and extra peaks at $44.8^{\circ}$ and $59.3^{\circ}$ in $5 \%$ and $10 \%$ Co-doped $\mathrm{ZnO}$ sample. However, the new and very small peaks are analyzed to 

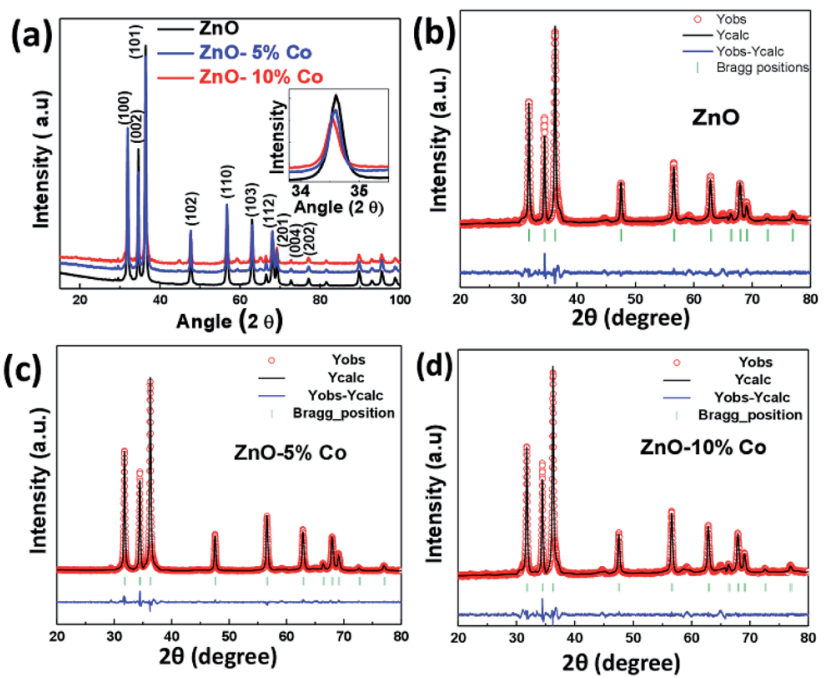

Fig. 3 (a) XRD patterns of $\mathrm{ZnO}$ and Co-doped $\mathrm{ZnO}$ at room temperature, $(b-d)$ Rietveld refined XRD patterns of $\mathrm{ZnO}$ and Codoped $\mathrm{ZnO}$ samples at room temperature. Dotted circles correspond to the XRD data and the lines are theoretical fits to the observed XRD data. The difference pattern between the observed data and the theoretical fit is shown at the bottom.

be Co metal impurity phase (JCPDS-01-1259) and $\mathrm{Co}_{3} \mathrm{O}_{4}$ (JCPDS76-1802) which may have appeared due to the clustering of cobalt either in the grain boundary or interstitial position. ${ }^{69}$ This grain boundary defect clustering may be responsible for the observed magnetic behavior in our samples. For further understanding, Rietveld refinement of the data was done which is shown in Fig. 3(b) and the refined parameters are given in Table 1. From the refined data, it can be seen that lattice parameter is not changed appreciably in $5 \%$ Co-doped $\mathrm{ZnO}$ sample (slight decrease) which is expected due to the small difference between the ionic radius of Co $(0.58 \AA)$ and $\mathrm{Zn}$ $(0.60 \AA)$. But in $10 \%$ Co-doped $\mathrm{ZnO}$ sample the lattice parameter is increased which might be due to the incorporation of $\mathrm{Co}^{2+}$ in interstitial sites. ${ }^{60}$ It may be inferred from the XRD data that in $5 \%$ Co-doped sample lattice parameter is slightly decreased due to the substitution of $\mathrm{Co}^{2+}$ with $\mathrm{Zn}^{2+}$ and in $10 \%$ Co-doped sample due to more amount of Co, there is an interstitial incorporation along with the substitutional incorporation of

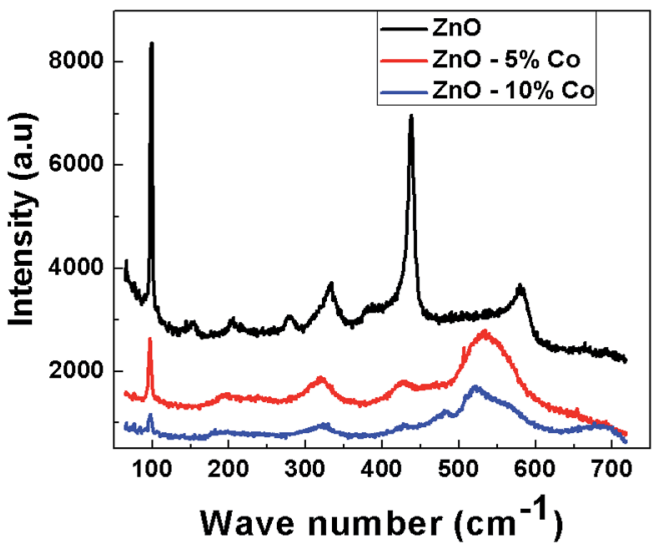

Fig. 4 Raman spectra recorded on $\mathrm{ZnO}$ and Co-doped $\mathrm{ZnO}$ samples at room temperature.

Co. The crystallite size is calculated from the positions of Bragg's reflection (from 110 planes) using the well known Debye-Scherrer's formula. ${ }^{83}$ The calculated crystallite size is found to increase with the increase in Co i.e. for $\mathrm{ZnO}$ crystal it is $27 \mathrm{~nm}$ while for $5 \%$ and $10 \%$ Co-doped $\mathrm{ZnO}$ crystals it is 30 and $33 \mathrm{~nm}$ respectively. This might be due to increased cobalt concentration in $\mathrm{ZnO}$ matrix which has increased the nucleation of particles as well as has enhanced the growth of crystallites.

Raman spectroscopy has been used to detect the disorder induced due to dopant incorporation in the host lattice, the presence of defects, etc. Fig. 4 shows the micro-Raman spectra of pure and Co-doped $\mathrm{ZnO}$ samples taken at room temperature in the range $65-715 \mathrm{~cm}^{-1}$. The optical phonons of wurtzite-type ZnO which belongs to point group $C_{6 \mathrm{v}}$ have an irreducible representation $\mathrm{A} 1+2 \mathrm{~B} 1+\mathrm{E} 1+2 \mathrm{E} 2 .{ }^{84} \mathrm{~A} 1$ and $\mathrm{E} 1$ are polar modes and hence can be split into transverse optical (TO) and longitudinal optical (LO) phonon modes. The B1 modes are silent in Raman scattering. ${ }^{85,86}$ The nonpolar E2 modes are Raman active and have two frequencies E2 (high) associated with vibration of the oxygen atom and E2 (low) associated with vibration of $\mathrm{Zn}$ atoms. $^{87}$

The sharp and strong peak at $437 \mathrm{~cm}^{-1}$ in the Raman spectra of $\mathrm{ZnO}$ can be assigned to $\mathrm{E} 2$ (high) mode of $\mathrm{ZnO}$ which is the strongest mode in wurtzite crystal structure. In the Co-doped

Table 1 Structural parameters of $\mathrm{ZnO}$ and Co-doped $\mathrm{ZnO}$ samples at room temperature obtained from Rietveld refinement

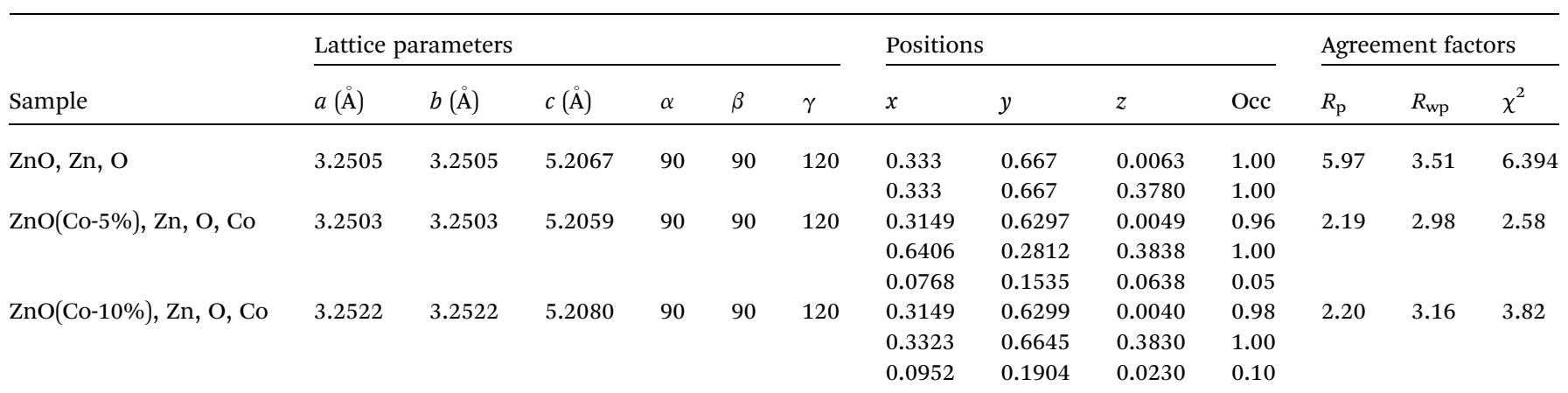


ZnO samples, this peak is found to be broadened and weakened with increasing Co content indicating that the crystal structure is disordered due to Co incorporation in the lattice. The peak at $99 \mathrm{~cm}^{-1}$ has been assigned to E2 (low) phonon mode of $\mathrm{ZnO}$. The E2 (low) mode is predominantly associated with nonpolar vibration of the heavier Zn-atom while E2 (high) mode is associated with the displacement of lighter O-atom. The Raman bands at 332 and $380 \mathrm{~cm}^{-1}$ are attributed to 2E2 (M) and A1 (TO) mode respectively. The intensity of the peak at $332 \mathrm{~cm}^{-1}$ has been decreased in Co-doped $\mathrm{ZnO}$, and even the peak at $380 \mathrm{~cm}^{-1}$ has disappeared due to disorder induced due to Co doping. The peak at $156 \mathrm{~cm}^{-1}$ may be related to defect induced mode. ${ }^{88}$ The peaks at 277 and $580 \mathrm{~cm}^{-1}$ are attributed to B1 (low) and $\mathrm{B} 1$ (high) phonons respectively. ${ }^{89}$ The peak at $580 \mathrm{~cm}^{-1}$ in $\mathrm{ZnO}$ has been shifted and broadened in Co-doped ZnO sample giving a remarkable feature around $532 \mathrm{~cm}^{-1}$ which can be assigned to local vibration mode related to Co that is bound with donor defects like doubly ionized oxygen vacancies and zinc interstitials. ${ }^{\mathbf{9 0}-\mathbf{9 2}}$ From XRD, and Raman spectra it can be deduced that incorporation of $\mathrm{Co}$ in $\mathrm{ZnO}$ leads to a decrease in crystal quality, but there is no change in wurtzite crystal structure.
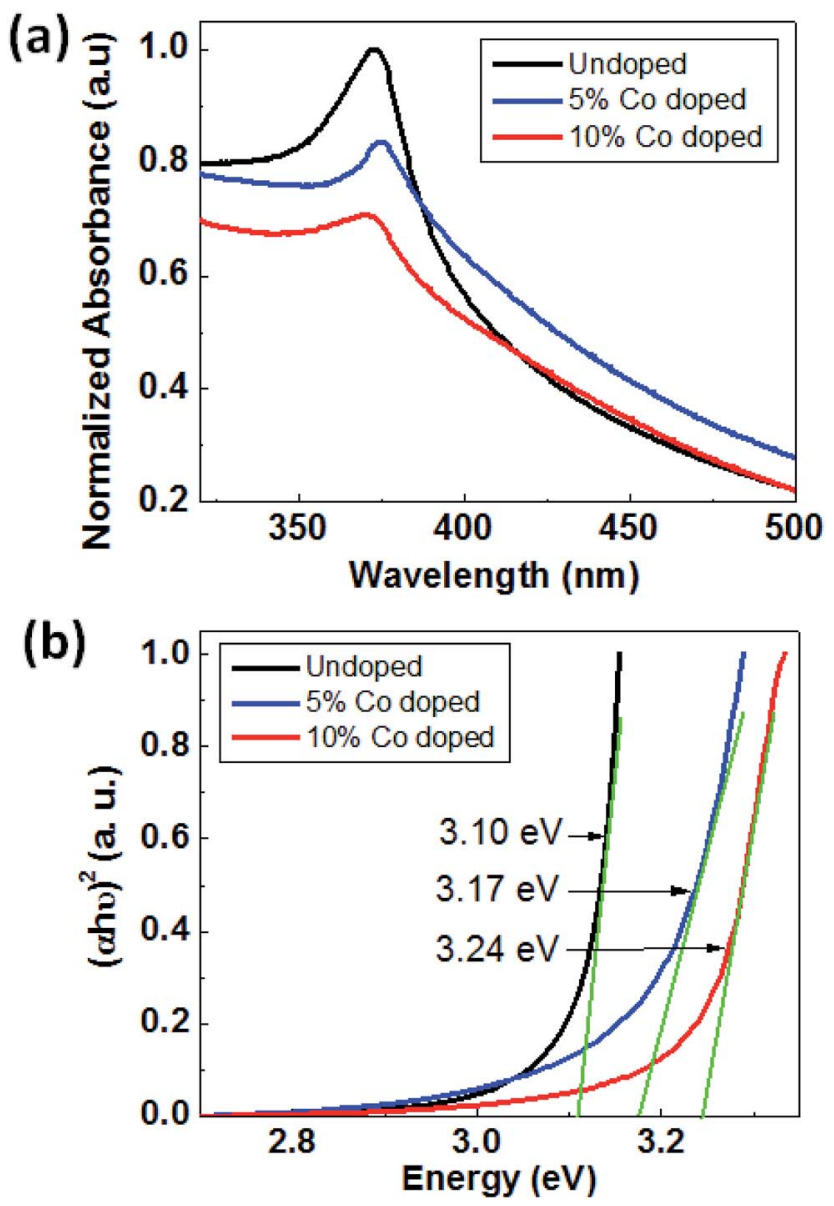

Fig. 5 (a) Absorbance vs. wavelength plot of $\mathrm{ZnO}, 5 \%$ Co-doped and $10 \%$-doped $\mathrm{ZnO}$ and (b) plot to estimate the direct optical band gap of $\mathrm{ZnO}, 5 \%$ Co doped and $10 \%$ doped $\mathrm{ZnO}$.
Fig. 5(a) shows the UV-visible absorption spectra of $\mathrm{ZnO}$ and Co-doped ZnO samples taken at room temperature. UV-Vis absorption spectra have been used to find out the changes in the energy band structure of $\mathrm{ZnO}$ due to Co doping. Primarily it is used to find out the band gap of the material. As shown in Fig. 4(a) the optical absorption of all the three samples show a strong absorption around 370-395 $\mathrm{nm}$, and the absorption edge is shifted to lower wavelength upon cobalt doping in $\mathrm{ZnO}$. The band gap energy of the samples can be calculated by using the following equation ${ }^{93}$ i.e.

$$
\alpha h \nu=A\left(h \nu-E_{\mathrm{g}}\right)^{1 / 2}
$$

where $\alpha$ is the absorption coefficient, $h \nu$ is the photon energy; $A$ is a constant, $E_{\mathrm{g}}$ is the bandgap energy. As $\mathrm{ZnO}$ is a direct band gap semiconductor, the optical band gap can be found out by extrapolation of the linear portion in the plot of $(\alpha h \nu)^{2}$ against $h \nu{ }^{94,95}$ Fig. 5(b) shows the bandgap as a function of cobalt concentration. The estimated bandgaps of $\mathrm{ZnO}, 5 \%$ Co-doped and $10 \%$ Co-doped $\mathrm{ZnO}$ are $3.10 \mathrm{eV}, 3.17 \mathrm{eV}$ and $3.24 \mathrm{eV}$ respectively. This blue shift in bandgap can be attributed to the phenomena called Burstein-Moss effect. ${ }^{96}$ It is reported in metal oxide system that particle size reduction results in a blue shift of bandgap due to quantum confinement effect. ${ }^{97}$ However it is also known that quantum confinement effect is not only the factor, doping can also modify the local lattice symmetry and introduce defect centers into the lattice which can make an alteration in the band structure and cause the large change in their properties. ${ }^{\mathbf{9 8 9 9}}$ Also, it is commonly known that with an increase in doping concentration, electrons populate states within conduction band pushing the Fermi level well inside the conduction band that is towards higher energy level leading to expansion of energy gap phenomena known as Burstein-Moss effect. It is about filling the bottom of the conduction band depending on the increase in the carrier concentration. With the increase in doping level there is increase in carrier concentration which are donated by interstitial zinc atoms or oxygen vacancies at room temperature, ${ }^{\mathbf{1 0 0}}$ which leads to blue shift in bandgap. As can be seen from PL data, with doping defects (zinc interstitial as well as oxygen vacancies) related peaks are enhanced. Here this may be a consequence of the incorporation of $\mathrm{Co}^{2+}$ in $\mathrm{ZnO}$ lattice. A similar type of phenomena has been observed by Ivill et al. ${ }^{\mathbf{1 0 1}}$ Mera et al., ${ }^{\mathbf{1 0 2}}$ Caglar et al., ${ }^{103}$ Husain et al. ${ }^{\mathbf{1 0 4}}$ It can be seen that there is the more blue shift with an increase in cobalt concentration. It is reported that more blue shift in 10\% Co-doped ZnO samples could be attributed to the combined effect of the optical transition to the excitonic state of $\mathrm{ZnO}$ nanoparticles and electronic transitions involving crystal-field split $3 \mathrm{~d}$ levels in $\mathrm{Co}^{2+}$ ions substituting $\mathrm{Zn}^{2+}$ ions responsible for observed blue shift. ${ }^{\mathbf{1 0 5}}$ These results further support our claim that the Co cations have effectively substituted into the wurtzite structure of $\mathrm{ZnO}$ and replaced the $\mathrm{Zn}$ cations sites.

The optical behavior of ZnO NPs and NRs is also studied by photoluminescence (PL) spectroscopy. Fig. 6(a and b) below show the normalized PL spectra of $\mathrm{ZnO}$ and Co-doped $\mathrm{ZnO}$ taken in two parts: first one from 370 to $550 \mathrm{~nm}$ and second one 

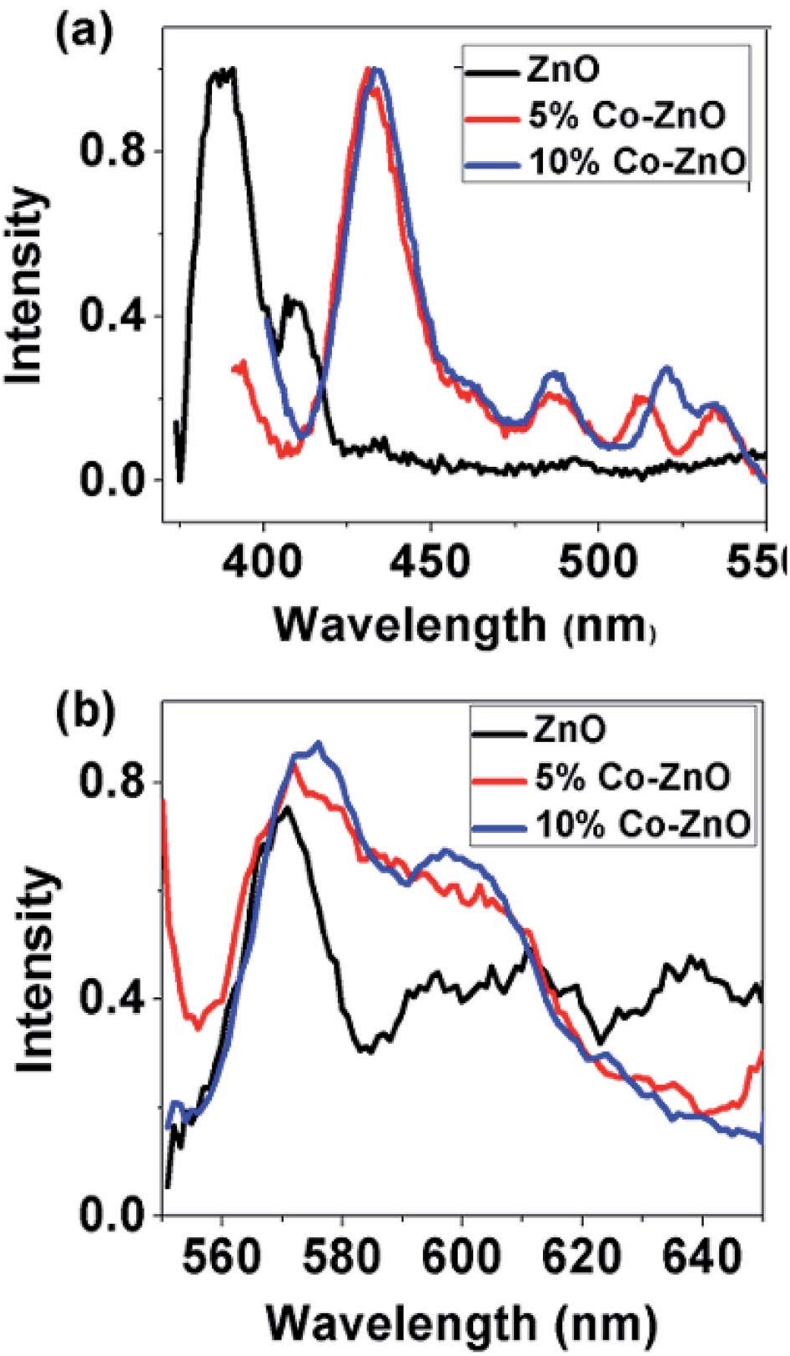

Fig. 6 Photoluminescence spectra of $\mathrm{ZnO}$, 5\% Co doped and 10\% doped $\mathrm{ZnO}$ at room temperature from (a) 370-550 nm and (b) 550$650 \mathrm{~nm}$.

from 550 to $650 \mathrm{~nm}$. The signature of strong excitonic band at $386 \mathrm{~nm}$ with no defect emission except a comparable weak band at $408 \mathrm{~nm}$ is observed in pure ZnO NPs. With doping several defect related peaks have appeared around $433 \mathrm{~nm}, 460 \mathrm{~nm}$, $486 \mathrm{~nm}, 520$ and $530 \mathrm{~nm}$. All these peaks are related to the transition of electrons from zinc interstitial $\left(\mathrm{Zn}_{\mathrm{i}}\right)$ in giving emission peak in violet-blue region (405-440 $\mathrm{nm}$ ), from oxygen vacancy $\left(\mathrm{V}_{\mathrm{O}}\right)$ giving green emission (490-610 $\mathrm{nm}$ ) and zinc vacancy $\left(V_{Z}\right)$ giving blue emission (450-460 nm). The defect emission peak is gradually increased with increasing doping concentration. From Fig. 6(b) it can be noticed that the defect peak around $520 \mathrm{~nm}$ has blue shifted and become broader with doping. Here it can be inferred that visible emission has enhanced with increase in doping concentration and this emission is due to the presence of $\mathrm{V}_{\mathrm{O}}$ and $\mathrm{Zn}_{\mathrm{i}} \cdot{ }^{106}$ There are several reports of quenching of visible emission in Co-doped ZnO NRs ${ }^{107-109}$ due to the dopant complexes acting as nonradiative centres ${ }^{\mathbf{1 1 0}}$ as well as anhilation of oxygen vacancy centres due to the presence of $\mathrm{Co}^{3+}$ ions ${ }^{\mathbf{1 1 1}}$ in the sample. But in our case, luminescence intensity of Co-doped $\mathrm{ZnO}$ nanorods has been increased in visible region which indicates that Codoping can improve surface states, enhance the number of defects and oxygen vacancies in doped nanorods ${ }^{\mathbf{1 1 2}}$ which is in agreement with Raman spectra.

To get information about the magnetic behavior of the Codoped ZnO nanostructures, field dependent magnetization $(M-H)$ measurements were carried out at $300 \mathrm{~K}$ and $2 \mathrm{~K}$. The $M-H$ curves measured at $300 \mathrm{~K}$ and $2 \mathrm{~K}$ show a diamagnetic nature for ZnO NPs which is shown in Fig. 7(a). However, the $M-H$ curves for doped (5\% and $10 \%$ ) samples show a small paramagnetic (PM) and superparamagnetic (SPM) like ordering at $300 \mathrm{~K}$ and $2 \mathrm{~K}$ respectively along with a definite FM ordering which is attested by the presence of hysteric nature at lower field

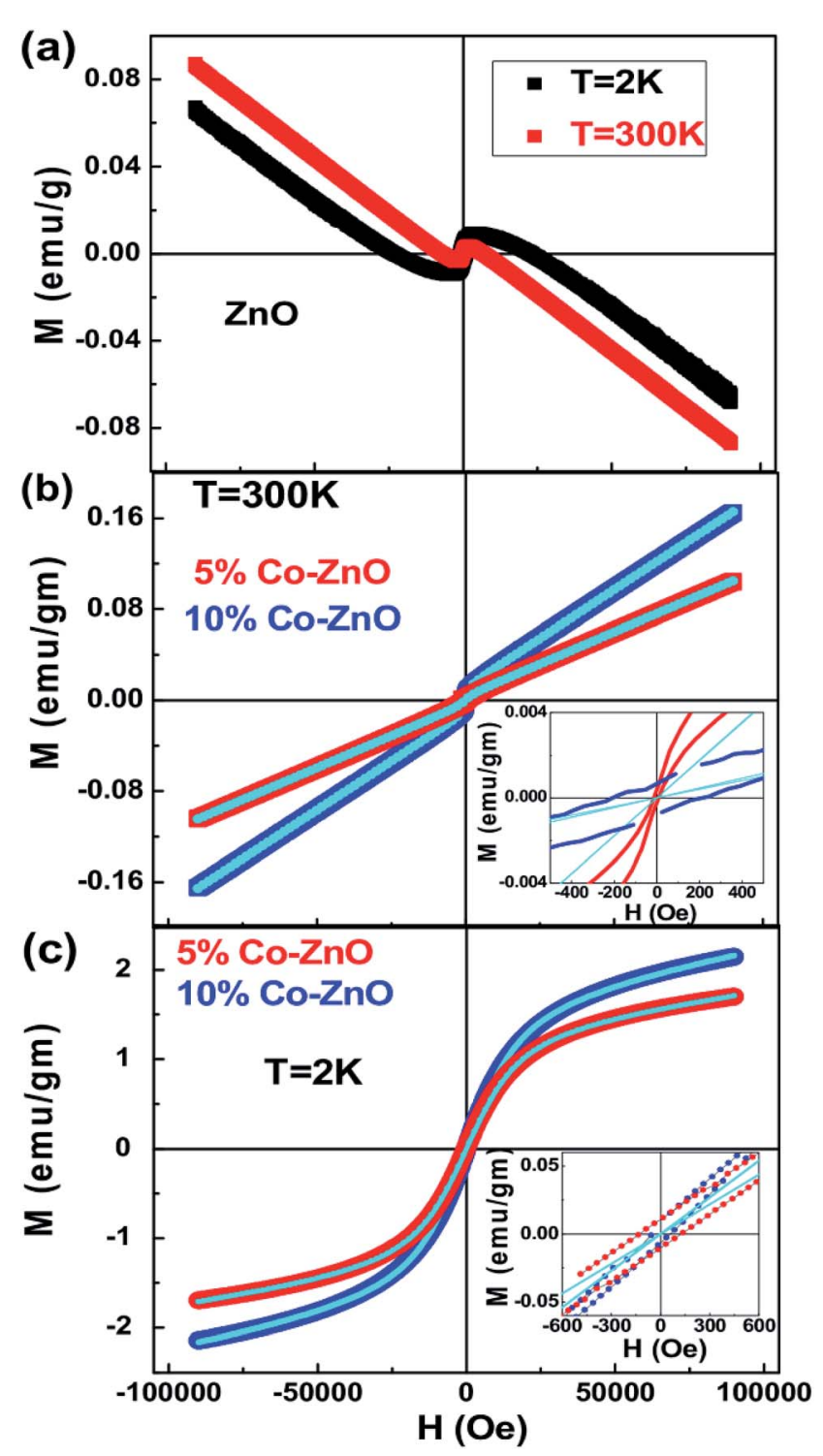

Fig. 7 Field variation of magnetization (a) $M-H$ curves at $2 \mathrm{~K}$ and $300 \mathrm{~K}$ for $\mathrm{ZnO}$ (b) $\mathrm{M}-\mathrm{H}$ curves measured at $300 \mathrm{~K}$ for Co-doped $\mathrm{ZnO}$ samples. (c) $M-H$ curves measured at $2 \mathrm{~K}$ for Co-doped $\mathrm{ZnO}$ samples. The solid lines represent the fit to the eqn (3) and the insets show the closure picture of the $\mathrm{M}-\mathrm{H}$ loops in the lower field regions. 
region (shown as the inset in Fig. $7(\mathrm{~b}$ and $\mathrm{c})$ ). The remanent magnetization $\left(M_{\mathrm{R}}\right)$ and coercivity $\left(H_{\mathrm{C}}\right)$ estimated are very small in the doped samples, but the $M_{\mathrm{R}}$ value is increased and the $H_{\mathrm{C}}$ is decreased at low temperature, i.e., at room temperature the $H_{\mathrm{C}}$ is more in both $5 \%$ (210 Oe) and 10\% (80 Oe) Co-doped samples than at $2 \mathrm{~K}(135$ Oe for $5 \%$ and 54 Oe for $10 \%$ Codoped samples). The $M_{\mathrm{R}}$ is increased from $1.8 \times 10^{-4} \mathrm{emu} \mathrm{g}^{-1}$ at $300 \mathrm{~K}$ to $0.008 \mathrm{emu}^{-1}$ at $2 \mathrm{~K}$ for $5 \%$ and from $6.6 \times$ $10^{-4} \mathrm{emu} \mathrm{g}^{-1}$ at $300 \mathrm{~K}$ to $0.011 \mathrm{emu} \mathrm{g}^{-1}$ at $2 \mathrm{~K}$ for $10 \%$ Co-doped sample. Although the magnetization is enhanced 10-15 times at $2 \mathrm{~K}$ from that at $300 \mathrm{~K}$, it is noted that the $M-H$ curves of doped samples do not saturate at high applied magnetic fields as $9 \mathrm{~T}$. Also, the net magnetization is increased in 10\% Co-doped sample in comparison to $5 \%$ Co-doped $\mathrm{ZnO}$ which indicates more dopant $(\mathrm{Co})$ incorporation in $10 \%$ doped sample. Similar kind of behavior is observed in Co-doped and Mn-doped $\mathrm{ZnO}$ nanocrystalline films prepared by pulsed laser deposition. ${ }^{\mathbf{1 1 3 - 1 1 5}}$

In general, this kind of an unusual magnetic behaviour can be understood due to the presence of two-magnetic components, i.e., a FM component that is easily saturated at very low fields and a linear component possible due to SPM or PM. But, there are not models which can be explained to describe the combined FM and SPM/PM behaviors in magnetization curves. Therefore, we have attempted to explain the FM and SPM contributions quantitatively using several theories, and in this attempt, we tried to fit the isothermal $M-H$ curve at $2 \mathrm{~K}$ with Langevin function:

$$
M=M_{\mathrm{S}} L\left(\mu H / K_{\mathrm{B}} T\right)
$$

where $M_{\mathrm{S}}$ is the saturation magnetization, $\mu$ is the average magnetic moment per particle; $K_{\mathrm{B}}$ is the Boltzmann constant. But the $M-H$ curves could not be fitted well with this function. From the $M-H$ curve, it can be thought that there is PM contribution, especially at the higher magnetic field. So, we tried to fit the $M-H$ curve with an equation containing some PM contribution i.e. with

$$
M=M_{\mathrm{S}} L\left(\mu H / K_{\mathrm{B}} T\right)+\chi H
$$

where $\chi$ is the paramagnetic susceptibility. It is observed that the $M-H$ plots were fitted well with the eqn (3) as shown in Fig. 7 (b and c). However the same is found to deviate at lower fields shown in the insets of the same figure which is due to the presence of FM contributions. The $M_{\mathrm{S}}$ value for $5 \%$ Co-doped sample is found out to be $1.42 \mathrm{emu}^{-1}\left(0.0149 \mu_{\mathrm{B}}\right.$ per atom) and for $10 \%$ Co-doped sample it is $1.75 \mathrm{emu} \mathrm{g}^{-1}\left(0.0184 \mu_{\mathrm{B}}\right.$ per atom) which are much smaller than the expected saturation magnetization of $\mathrm{Co}^{2+}$ ions ( $3 \mu_{\mathrm{B}}$ per Co) from which it can be inferred that only a fraction of Co atoms participate in FM, the rest contribute to the observed SPM/PM signals. The results suggest that the Co-doped samples exhibit ferromagnetism along with SPM/PM behavior at $2 \mathrm{~K}$ and $300 \mathrm{~K}$ with reduced remanent magnetization. With the increase in Co concentration, the magnetization is enhanced indicating more incorporation of Co atoms in $\mathrm{ZnO}$ matrix. To get detailed information about the magnetic behavior, the temperature variation of magnetization ( $M-T$ curves) was measured under zero field cooled (ZFC) and field cooled (FC) condition at 100 Oe and shown in Fig. 8. The pure $\mathrm{ZnO}$ sample shows very weak magnetic in nature, however, the Co-doped samples show a low magnetization values but with a clear magnetic ordering at lower temperature in their ZFC and FC curves. The presence of paramagnetic component is also confirmed from the steep upturn in the magnetization value below and FC curves. The presence of paramagnetic component is also confirmed from the steep upturn in the magnetization value below around $50 \mathrm{~K}$ whereas the presence of irreversibility between ZFC and FC curve indicates the presence of ferromagnetic ordering in the doped samples. Lower magnetization values and irreversibility behavior in ZFC and FC curves with the application of small magnetic fields suggest the presence of magnetic disorder in the samples. It is interesting to note that in the case of both doped samples the splitting between ZFC and FC curve occurs

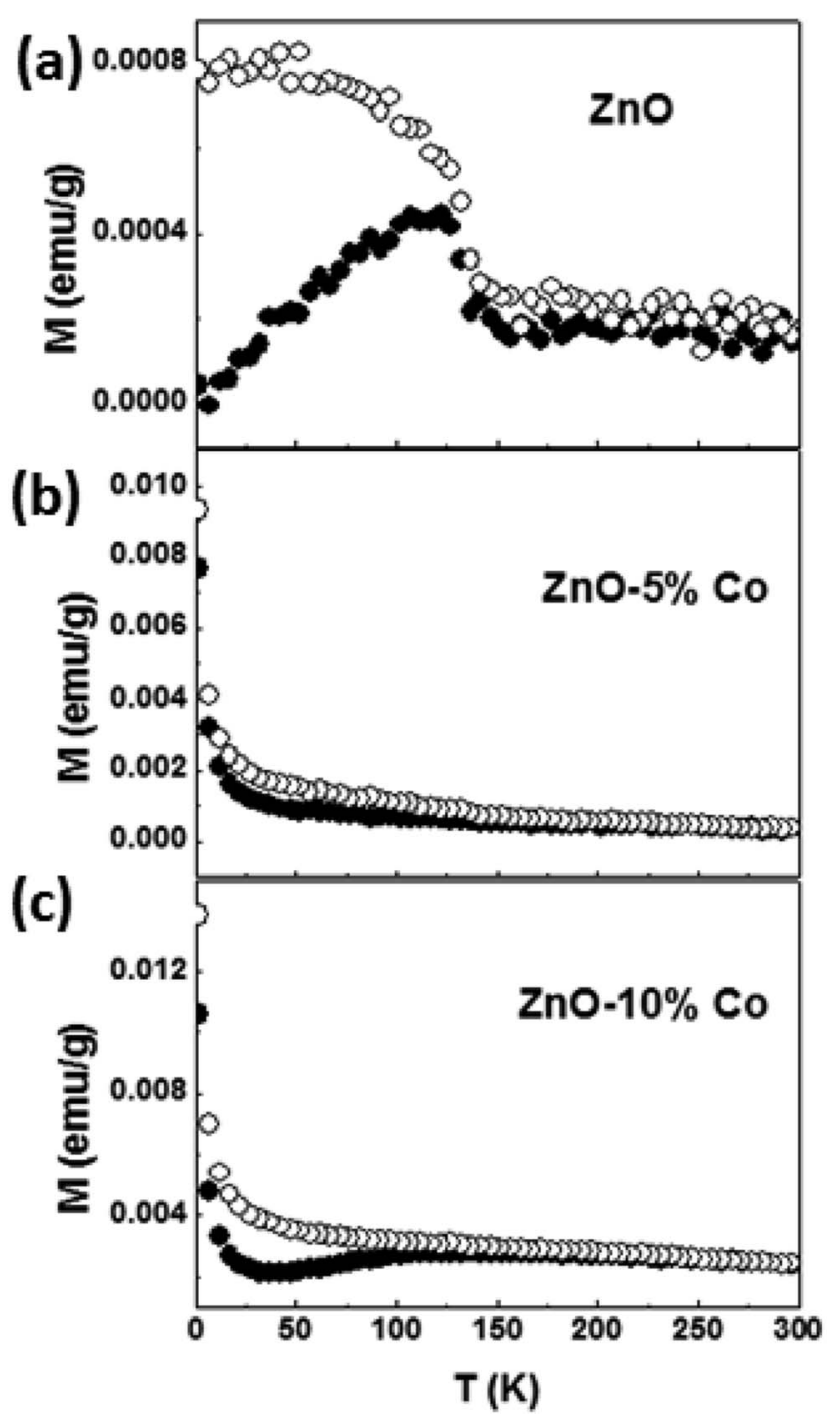

Fig. 8 Temperature variation of magnetization for the Co-doped $\mathrm{ZnO}$ samples measured under 100 Oe in zero-field-cooled (ZFC) and field cooled (FC) modes. Closed and open symbols represent ZFC and FC respectively. 
around $250 \mathrm{~K}$, but a weak ferromagnetic ordering exists at $300 \mathrm{~K}$ in $M-H$ plots taken at $300 \mathrm{~K}$. In $10 \%$ Co-doped sample the enhanced difference between the ZFC and FC below $140 \mathrm{~K}$ reflects the blocking temperature $T_{\mathrm{B}}$ of the assembly of SPM particles. Similarly, in 5\% Co-doped sample the transition at around $50 \mathrm{~K}$ is characterized by a cusp in the ZFC curve indicating an FM to SPM or an FM to PM transition. Superparamagnetism arises because of the inhomogeneities created due to the formation of NPs, NRs of different sizes. The steep increase in magnetization with the decrease in temperature below around $50 \mathrm{~K}$ in the $M v s$. $T$ curve is characteristic of all DMS materials possibly due to the defects. Raman spectra indicate the presence of defects in doped $\mathrm{ZnO}$ sample like doubly ionized oxygen vacancies and zinc interstitials which are expected to play the role for the kind of magnetic behavior observed in Co-doped $\mathrm{ZnO}$ samples. It can be noted that in spite of the presence of defects (as evidenced from Raman spectra and PL), the diamagnetic behavior is observed in $\mathrm{ZnO}$ samples. This confirms that defects alone are not sufficient to account for the observed ferromagnetic behavior of doped samples. Also another impurity phase i.e. $\mathrm{Co}_{3} \mathrm{O}_{4}$ is antiferromagnetic which rules out the possibility of incorporating ferromagnetism. There are several reports suggesting the ferromagnetism arising due to impurity segregation at grain boundaries of oxides. In our case, it is confirmed from XRD that cobalt clustering has taken place in Co-doped samples. In this connection, we believe that the observed ferromagnetism may have originated due to the exchange interaction between the localized d electrons in $\mathrm{Co}^{2+}$ atoms and free carriers generated due to Co-doping in $\mathrm{ZnO}$ nanorods along with cobalt clustering and defects.

\section{Conclusions}

In summary, structural, optical and magnetic properties of $\mathrm{ZnO}$ and 5\%, 10\% Co-doped ZnO NPs and NRs synthesized by a simple wet chemical route have been studied. Powder X-ray diffraction, high-resolution transmission electron microscopy, selected area electron diffraction pattern confirm the formation of NPs and NRs in un-doped as well as Co-doped ZnO samples. However, the production of NRs is more visible with the increase in Co-content. Raman spectroscopy indicates the disorder and defects induced due to Co-doping and shifting and broadening of the bands at $437 \mathrm{~cm}^{-1}$ and $579 \mathrm{~cm}^{-1}$ in microRaman study of Co-doped $\mathrm{ZnO}$ samples indicate the incorporation of Cobalt in $\mathrm{ZnO}$. Blue shift in band gap attributed due to Burstein-Moss effect may be a consequence of the incorporation of $\mathrm{Co}^{2+}$ in $\mathrm{ZnO}$ lattice. Field-dependent magnetization ( $M-H$ curve) measurement exhibits the diamagnetic behavior of un-doped $\mathrm{ZnO}$ at $2 \mathrm{~K}$ and room temperature while Co-doped $\mathrm{ZnO}$ samples show coexistence of superparamagnetic and ferromagnetic behavior at room temperature and $2 \mathrm{~K}$. Observed ferromagnetism may have originated due to the exchange interaction between the localized d electrons in $\mathrm{Co}^{2+}$ atoms and free carriers generated due to Co-doping as well as due to cobalt clustering in the Co-doped samples.

\section{Conflicts of interest}

There are no conflicts of interest to declare.

\section{Acknowledgements}

The authors (Anupama Chanda and Jai Singh) wish to acknowledge, University Grants Commission for providing UGC-BSR Research Start-Up-Grant (No. F.30-12/2014(BSR)) to carry out this work. M. Vasundhara would like to thank Department of Science and Technology for partially supporting this work. A. Chanda would also like to acknowledge Dr Prashant Shukla for his valuable discussion regarding curve-fitting and Image J software.

\section{References}

1 M. S. von and D. Read, Proc. IEEE, 2003, 91, 715.

2 S. A. Wolf, D. D. Awschalom, R. A. Buhrman, J. M. Daughton, M. S. von, M. L. Roukes, A. Y. Chtchelkanova and D. M. Treger, Science, 2001, 294, 1488.

3 T. Dietl, Semicond. Sci. Technol., 2002, 17, 377.

4 C. Chappert, A. Fert and F. Nguyen Van Dau, Nat. Mater., 2007, 6, 813.

5 J. K. Furdyna and J. Kossut, in Semiconductors and Semimetals, ed. R. K. Williardson and A. C. Beer, Academic, New York, 1988, p. 25.

6 (a) Y. Ohno, D. K. Young, B. Beschoten, F. Matsukura, H. Ohno and D. D. Awschalom, Nature, 1999, 402, 790; (b) H. Ohno, D. Chiba, F. Matsukura, T. Omiya, E. Abe, T. Dietl, Y. Ohno and K. Ohtani, Nature, 2000, 408, 944.

7 Semiconductor and Semimetals, Diluted Magnetic Semiconductors, ed. J. Furdyna and J. Kossut, Academic Press, Boston, 1988, vol. 25.

$8 \mathrm{~J}$. Kossut and W. Dobrowolski, Handbook of Magnetic Materials, ed. K. H. J. Buschow, North-Holland, Amsterdam, 1993, vol. 7.

9 T. Dietl, J. Jaroszynski, G. Grabecki, J. Wrobel, M. Sawicki, T. Skoskiewicz, E. Kaminskaz, A. Piotrowskaz, G. Karczewski, T. Wojtowicz and J. Kossut, Semicond. Sci. Technol., 1996, 11, 1618.

$10 \mathrm{H}$. Ohno, H. Munekata, T. Penny, S. von Molnar and L. L. Chang, Phys. Rev. Lett., 1992, 68, 2664.

$11 \mathrm{H}$. Ohno, A. Shen, F. Matsukura, A. Oiwa, A. Endo, S. Katsumoto and Y. Iye, Appl. Phys. Lett., 1996, 69, 363.

12 M. Overby, A. Chernyshov, L. P. Rokhinson, X. Liu and J. K. Furdyna, Appl. Phys. Lett., 2008, 92, 192501.

13 Z. Li, J. A. Mol, L. Lagae, G. Borghs, R. Mertens and W. V. Roy, Appl. Phys. Lett., 2008, 92, 112513.

14 D. Wu, P. Wei, E. Johnston-Halperin, D. D. Awschalom and J. Shi, Phys. Rev. B: Condens. Matter Mater. Phys., 2008, 77, 125320.

15 M. Watanabe, J. Okabayashi, H. Toyao, T. Yamaguchi and J. Yoshino, Appl. Phys. Lett., 2008, 92, 082506.

16 S. Mack, R. C. Myers, J. T. Heron, A. C. Gossard and D. D. Awschalom, Appl. Phys. Lett., 2008, 92, 192502. 
17 D. Chiba, M. Yamanouchia, F. Matsukuraa, T. Dietl and H. Ohno, J. Magn. Magn. Mater., 2007, 310, 2078.

18 M. Zajac, J. Gosk, E. Grzanka, S. Stelmakh, M. Palczewska, A. Wysmolek, K. Korona, M. Kaminska and A. Twardowski, J. Alloys Compd., 2008, 456, 324.

19 V. V. Rylkov, B. A. Aronzon, Y. A. Danilov, Y. N. Drozdov, V. P. Lesnikov, K. I. Maslakov and V. V. Podolíski, J. Exp. Theor. Phys., 2005, 100, 742.

20 N. A. Sobolev, M. A. Oliveira, R. M. Rubinger, A. J. Neves, M. C. Carmo, V. P. Lesnikov, V. V. Podolskii, Y. A. Danilov, E. S. Demidov and G. N. Kakazei, J. Supercond. Novel Magn., 2007, 20, 399.

21 T. Schallenberg and H. Munekata, J. Cryst. Growth, 2007, 301, 623.

22 D. L. Hou, R. B. Zhao, H. J. Meng, L. Y. Jia, X. J. Ye, H. J. Zhou and X. L. Li, Thin Solid Films, 2008, 516, 3223.

23 A. I. Rykov, K. Nomura, J. Sakuma, C. Barrero, Y. Yoda and T. Mitsui, Phys. Rev. B: Condens. Matter Mater. Phys., 2008, 77, 014302.

24 Y. Wang, G. Pang, Y. Chen, S. Jiao, D. Wang and S. Feng, J. Solid State Chem., 2008, 181, 217.

25 J. Zhang, R. Skomski, L. P. Yue, Y. F. Lu and D. J. Sellmyer, J. Phys.: Condens. Matter, 2007, 19, 256204.

26 P. F. Xing, Y. X. Chen, S. S. Yan, G. L. Liu, L. M. Mei, K. Wang, X. D. Han and Z. Zhang, Appl. Phys. Lett., 2008, 92, 022513.

27 D. Berardan, E. Guilmeau and D. Pelloquin, J. Magn. Magn. Mater., 2008, 320, 983.

28 Q. Xu, H. Schmidt, H. Hochmuth, M. Lorenz, A. Setzer, P. Esquinazi, C. Meinecke and M. Grundmann, J. Phys. D: Appl. Phys., 2008, 41, 105012.

29 S. Zhou, K. Potzger, G. Talut, H. Reuther, K. Kuepper, J. Grenzer, Q. Xu, A. Mucklich, M. Helm, J. Fassbender and E. Arenholz, J. Phys. D: Appl. Phys., 2008, 41, 105011.

30 J. Fan and R. Freer, J. Mater. Sci., 1993, 28, 1391.

31 J. Jie, G. Wang, Q. Wang, Y. Chen, X. Han, X. Wang and J. G. Hou, J. Phys. Chem. B, 2004, 108, 11976.

32 X. Wang, R. K. Zheng, Z. Liu, H. P. Ho, J. B. Xu and S. P. Ringer, Nanotechnology, 2008, 19, 455702.

33 T. Polek, M. Semen'ko, T. Endo, Y. Nakamura, G. S. Lotey and A. Tovstolytkin, Nanoscale Res. Lett., 2017, 12, 180.

34 S. J. Pearton, D. P. Norton, K. Ip, Y. W. Heo and T. Steiner, Superlattices Microstruct., 2003, 34, 3.

35 M. H. Huang, S. Mao, H. Feick, H. Yan, Y. Wu, H. Kind, E. Weber, R. Russo and P. Yang, Science, 2001, 292, 1897.

36 Q. Wan, Q. H. Li, Y. J. Chen, T. H. Wang, X. L. He, J. P. Li and C. L. Lin, Appl. Phys. Lett., 2004, 84, 3654.

37 S. Sakthivel, B. Neppolian, M. V. Shanka, B. Arabindoo, M. Palanichamy and V. Muruguesan, Sol. Energy Mater. Sol. Cells, 2003, 77, 65.

38 A. Mclaren, T. Valdes-Solis, G. Li and S. C. Tsang, J. Am. Chem. Soc., 2009, 131, 12540.

39 K. Kim, T. Moon, M. Lee, J. Kang, Y. Jeon and S. Kim, Solid State Sci., 2011, 13, 1735.

40 E. Guillen, E. Azaceta, L. M. Peter, A. Zukal, R. Tena-Zaera and J. A. Anta, Energy Environ. Sci., 2011, 4, 3400.
41 K. Matsubara, P. Fons, K. Iwata, A. Yamada, K. Sakurai, H. Tampo and S. Niki, Thin Solid Films, 2003, 431, 369.

42 G. S. Lotey, J. Singh and N. K. Verma, J. Mater. Sci.: Mater. Electron., 2013, 24(9), 3611.

43 G. S. Lotey, Z. Jindal, V. Singhi and N. K. Verma, Mater. Sci. Semicond. Process., 2013, 16(6), 2044.

44 P. V. Raleaooa, A. Roodt, G. G. Mhlongo, D. E. Motaung, R. E. Kroon and O. M. Ntwaeaborwa, Phys. B, 2017, 507, 13.

45 N. Karar, H. Chander and S. M. Shivaprasad, Appl. Phys. Lett., 2004, 85, 5058.

46 N. Padmavathy and R. Vijayaraghavan, Sci. Technol. Adv. Mater., 2008, 9, 035004.

47 T. Dietl, H. Ohno, F. Matsukura, J. Cibert and D. Ferrand, Science, 2000, 287, 1019.

48 H. T. Lin, T. S. Chin, J. C. Shih, S. H. Lin, T. M. Hong, R. T. Huang, F. R. Chen and J. J. Kai, Appl. Phys. Lett., 2004, 85, 621.

49 Z. Jin, T. Fukumura, M. Kawasaki, K. Ando, H. Saito, T. Sekiguchi, Y. Z. Hoo, M. Murakami, Y. Matsumuto, T. Hasegawa and H. Koinuma, Appl. Phys. Lett., 2001, $78(24), 3824$.

50 R. D. Shannon, Acta Crystallogr., Sect. A: Cryst. Phys., Diffr., Theor. Gen. Crystallogr., 1976, 32(5), 751.

51 K. Sato and H. K. Yoshida, Phys. E, 2001, 10(1-3), 251.

52 K. Ueda, H. Tabota and T. Kawai, Appl. Phys. Lett., 2001, 79, 988.

53 C. C. Wang, M. Liu, B. Y. Man, C. S. Chen, S. Z. Jiang, S. Y. Yang, X. G. Gao, S. C. Xu, B. Hu, Z. C. Sun, J. J. Guo and J. Hou, AIP Adv., 2012, 2, 012182.

54 J. Mohapatra, D. K. Mishra, D. Mishra, A. Perumal, V. R. R. Medicherla, D. M. Phase and S. K. Singh, Mater. Res. Bull., 2012, 47, 1417.

55 B. Pal, S. Dhara, P. K. Giri and D. Sarkar, J. Alloys Compd., 2014, 615, 378.

56 S. Chakraborty, S. Sarwar and P. Chakrabarty, J. Phys. Chem. $B, 2013,117,13397$.

57 L. Zhang, X. Liu, C. Geng, H. Fang, Z. Lian, X. Wang, D. Shen and Q. Yan, Inorg. Chem., 2013, 52, 10167.

58 E. W. Seeling, B. Tang and A. Yamilov, Mater. Chem. Phys., 2003, 80, 257.

59 S. J. Chen, G. R. Wang and Y. C. Liu, J. Lumin., 2009, 129, 340.

60 I. Djerdj, G. Garnweitner, D. Arcon, M. Pregeli, Z. Jaqlicic and M. Niedegrberger, J. Mater. Chem., 2008, 18, 5208.

61 R. Podila, W. Queen, A. Nath, J. T. Avantes, A. L. Schoenhalz, A. Fazzio, G. M. Dalpian, J. He, S. J. Hwu, M. J. Skove and A. M. Rao, Nano Lett., 2010, 10, 1383.

62 J. M. D. Coey, M. Venkatesan and C. B. Fitzgerald, Nat. Mater., 2005, 4, 173.

63 N. Khare, M. J. Kappers, M. Wei, M. G. Blamire and J. L. MacManus-Driscoll, Adv. Mater., 2006, 18, 1449.

64 S. A. Chambers, T. Droubay, C. M. Wang, A. S. Lea, R. F. C. Farrow, L. Folks, V. Deline and S. Anders, Appl. Phys. Lett., 2003, 82, 1257.

65 F. C. Kartawidjaja, Z. Y. Lim, S. L. G. Ng, Y. Zhang and J. Wang, J. Am. Ceram. Soc., 2010, 93, 3798. 
66 X. J. Liu, X. Y. Zhu, J. T. Luo, F. Zeng and F. Pan, J. Alloys Compd., 2009, 482, 224.

67 M. N. Lin, H. S. Hsu, J. Y. Lai, M. C. Guo, C. Y. Lin, et al., Appl. Phys. Lett., 2011, 98, 212509.

68 H. S. Hsu, J. C. A. Huang, S. F. Chen and C. P. Liu, Appl. Phys. Lett., 2007, 90, 102506.

69 A. Aravindh, S. Devi and I. S. Roqan, $R S C A d v .$, 2016, 6, 50818.

70 N. S. Singh, S. D. Singh and S. K. Bandopadhyaya, Phys. Procedia, 2014, 54, 2.

71 V. Gandhi, R. Ganesan, H. H. A. Syedahamed and M. Thaiyan, J. Phys. Chem. C, 2014, 118, 9715.

72 J. Cui, Q. Zeng and U. J. Gibson, J. Appl. Phys., 2006, 99, 08M113.

73 L. Yanmei, F. Qingqing, W. Mingzai, Li. Yan, Lv. Qingrong, Z. Jun and W. Baoming, J. Phys. D: Appl. Phys., 2007, 40, 4592.

74 W. L. Li, Y. Zhao and W. D. Fei, J. Sol-Gel Sci. Technol., 2010, 54(3), 335.

75 Y. Liu, Q. Fang, M. Wu, Y. Li, Q. Lv, J. Zhou and B. Wang, J. Phys. Appl. Phys., 2007, 40(15), 4592.

76 J. Cui, Q. Zeng and U. J. Gibson, J. Appl. Phys., 2006, 99(8), $08 \mathrm{M} 113$.

77 K. L. Foo, U. Hashim, K. Muhammad and C. H. Voon, Nanoscale Res. Lett., 2014, 9, 429.

78 D. A. Schwartz, N. S. Norberg, Q. P. Nguyen, J. M. Prker and D. R. Gamelin, J. Am. Chem. Soc., 2003, 125, 13205.

79 J. Singh, P. Kumar, D. J. Late, T. Singh, M. A. More, D. S. Joag, R. S. Tiwari, K. San Hui and O. N. Srivastava, Dig. J. Nanomater. Bios., 2012, 7, 525.

80 V. K. Sharma, M. Najim, A. K. Srivastava and G. D. Varma, J. Magn. Magn. Mater., 2012, 324, 683.

81 E. Gungor, T. Gungor, D. Caliskanb, A. Ceylanc and E. Ozbay, Appl. Surf. Sci., 2014, 318, 309.

82 L. W. Yeng, X. L. Wu, T. Qui, G. G. Siu and P. K. Chu, J. Appl. Phys., 2006, 99, 074303.

83 S. Singhal, J. Kaur, T. Namgyal and R. Sharma, Phys. B, 2012, 407, 1223.

84 S. Sahoo, G. L. Sharma and R. S. Katiyar, J. Raman Spectrosc., 2012, 43, 72.

85 Y. Q. Chang, P. W. Wang, S. L. Ni, Y. Long and X. D. Li, J. Mater. Sci. Technol., 2012, 23, 313.

86 R. Loudon, Adv. Phys., 1964, 13, 423.

87 B. Pal and P. K. Giri, J. Nanosci. Nanotechnol., 2011, 11, 1.

88 C. Bundesmann, N. Ashkenov, M. Schubert, D. Spemann, T. Buzz, E. Kaidaschev, M. Lorenz and M. Grundmann, Appl. Phys. Lett., 2003, 83, 4631.

89 F. J. Manjon, B. Mari, J. Serrano and A. H. Romero, J. Appl. Phys., 2005, 97, 053516.
90 J. M. D. Coey, M. Venkatesan and C. B. Fitzgerald, Nat. Mater., 2005, 4, 173.

91 J. H. Lee, C. H. Park, S. Y. Jeong, K. J. Yee, C. R. Cho, M. H. Jung and D. J. Chadi, Appl. Phys. Lett., 2006, 88, 062504.

92 X. Wang, J. Xu, B. Zhang, H. Yu, J. Wang, X. Zhang, J. Yu and Q. Li, Adv. Mater., 2006, 18, 2476.

93 R. A. Vanleeuwen, C. J. Hung, D. R. Kammler and J. A. Swizer, J. Phys. Chem., 1995, 99, 15247.

94 U. Koch, A. Fojtik, H. Weller and A. Henglein, Chem. Phys. Lett., 1985, 122, 507.

95 L. Brus, J. Phys. Chem., 1986, 90, 2555.

96 B. E. Sernelius, K. F. Berggren, Z. C. Jin, I. Hamberg and C. G. Graqvist, Phys. Rev. B: Condens. Matter Mater. Phys., 1988, 37, 10244.

97 Z. Sun, H. J. Sue and N. Miyatake, J. Phys. Chem. C, 2008, 112, 16002.

98 S. Das, S. Kar and S. Chaudhuri, J. Appl. Phys., 2006, 99, 114303.

99 C. Du and H. Yang, RSC Adv., 2013, 3, 13990.

100 Z. B. Bahsi and A. Y. Oral, Opt. Mater., 2007, 29, 672.

101 M. Ivill, S. J. Pearton, S. Rawal, L. Leu, P. Sadik, R. Das, A. F. Hebard, M. Chisholm, J. D. Budai and D. P. Norton, New J. Phys., 2008, 10, 065002.

102 J. Mera, C. Cordoba, J. Doria, A. Gomez, C. Paucar, D. Fuchs and O. Moran, Thin Solid Films, 2012, 525, 13.

103 Y. Caglar, J. Alloys Compd., 2013, 560, 181.

104 S. Husain, L. A. Alkhtaby, I. Bhat, E. Giorgetti, A. Zoppi and M. M. Miranda, J. Lumin., 2014, 154, 430.

105 P. Koidl, Phys. Rev. B: Solid State, 1977, 15, 493.

106 X. Liu, X. Wu, H. Cao and R. P. H. Chang, J. Appl. Phys., 2004, 95, 3141.

107 H. Hao, M. Qin and P. Li, J. Alloys Compd., 2012, 515, 143.

108 D. S. Bohle and C. J. Spina, J. Phys. Chem. C, 2010, 114, 18139.

109 S. Shi, Y. Yang, J. Xu, X. Zhang, G.-H. Hu and Z.-M. Dang, J. Alloys Compd., 2013, 576, 59.

110 V. A. L. Roy, A. B. Djurisic, H. Liu, X. X. Zhang, Y. H. Liung, M. H. Xie, J. Gao, H. F. Lui and C. Surya, Appl. Phys. Lett., 2004, 84, 756.

111 S. Ezhilvalvan and T. R. N. Kutty, J. Mater. Sci., 1996, 7, 137. 112 W. Baiqi, S. Xudong, F. Qiang, J. Iqbal, L. Yan, F. Honggang and Y. Dapeng, Phys. E, 2009, 41, 413.

113 Q. Li, Y. Wang, L. Fan, J. Liu, W. Konga and B. Yea, Scr. Mater., 2013, 69, 694.

114 S. Venkatesh, A. Baras, J.-S. Lee and I. S. Roqan, AIP Adv., 2016, 6, 035019.

115 A. Ney, V. Ney, S. Ye, K. Ollefs and T. Kammermeier, Phys. Rev. B: Condens. Matter Mater. Phys., 2010, 82, 041202(R). 